\title{
Stosowanie i wytwarzanie układów trójwarstwowych do budowy elementów aparatury procesowej
}

\author{
Application and manufacture of three-layer systems \\ for the construction of process equipment components
}

\section{Streszczenie}

W pracy przedstawiono wyniki badań makroskopowych, mikrotwardości, określono własności mechaniczne dwóch układów trójwarstwowych składających się z cyrkonu-tytanu-stali i tytanu-stali-stali po platerowaniu wybuchowym zginania oraz odrywanie, a także analizę równoważnej grubości przetopień RGP.

Słowa kluczowe: zgrzewanie wybuchowe; obserwacje makroskopowe; badania mechaniczne; badania mikrotwardości; analiza RGP

\begin{abstract}
The work presents the results of the research of macroscopic, microhardness tests, RGP penetration thickness analysis and mechanical properties of two three-layer systems consisting of zirconium-titanium-steel and titanium-steel-steel after explosion cladding.
\end{abstract}

Keywords: explosive welding; macroscopic observation; mechanical testing; hardness testing; analysis of RGP

\section{Wstęp}

Współczesna praktyka zna wiele metod zgrzewania. Zaliczamy do nich m.in. zgrzewanie elektryczne, gazowe, oporowe, czy wybuchowe. Zasadniczą cechą trzech pierwszych sposobów jest wykorzystanie ciepła do uzyskania połączenia materiałów. W przypadku zgrzewania wybuchowego ciepło odgrywa drugorzędną rolę a bywa, że jest wręcz szkodliwe dla uzyskania poprawnych właściwości złącza. Zasadnicze znaczenie ma ciśnienie $\mathrm{w}$ punkcie kontaktu zderzających się materiałów. Taki mechanizm umożliwia uzyskanie połączeń materiałów, których nie da się połączyć pozostałymi wymienionymi metodami $[1,2]$.

Platery są wykorzystywane do budowy elementów aparatury chemicznej i procesowej. Technologia pozwala na wytwarzanie ścian sitowych wymienników ciepła, dennic i zbiorników, zwijanych na walcach płaszczy aparatów. Platerowanie wybuchowe służy również do wytwarzania złączy i styków prądowych oraz łączników spawalniczych [3].

Koszt produkcji sprawia, że technologia ta w dużej mierze jest opłacalna. Dzięki niej można oszczędzać materiały deficytowe, które są stosunkowo drogie. Elementy platerowane wybuchowo w głównej mierze znajdują zastosowanie w środowiskach agresywnych. Materiał podstawowy z reguły ma większą grubość niż materiał nakładany oraz lepsze własności wytrzymałościowe. Z kolei materiał nakładany cechuje się znaczną odpornością na korozję czy przewodnością elektryczną [4].

\section{Badania własne}

Badaniom poddano plater trójwarstwowy składający się z cyrkonu, tytanu oraz stali. Materiałem nakładanym był cyrkon (Zr 700) o grubości $10 \mathrm{~mm}$. Warstwę pośrednią stanowił tytan (Ti Gr.1) o grubości $5 \mathrm{~mm}$. Materiałem podstawowym była stal ferrytyczno-austenityczna (LDX) o grubości $150 \mathrm{~mm}$.

Kolejnym badanym trimetalem był układ składający się z tytanu, stali austenitycznej i stali duplex (LDX). Materiałem nakładanym był tytan (Ti Gr.1) o grubości $10 \mathrm{~mm}$. Warstwę pośrednią stanowiła stal 304L o grubości $4 \mathrm{~mm}$. Materiałem podstawowym była stal ferrytyczno-austenityczna (LDX) o grubości $220 \mathrm{~mm}$.

Skład chemiczny oraz własności mechaniczne stali podano w tablicach I i II, a własności tytanu i cyrkony w tablicy III.

Platery, wykonane w Zakładzie Technologii Wysokoenergetycznych EXPLOMET w Opolu, zostały poddane badaniom wytrzymałości na ścinanie, zginanie oraz odrywanie. Ponadto wykonano badania metalograficzne makroskopowe, badania mikrotwardości i dokonano analizy równoważnej grubości przetopień RGP.

Badania mechaniczne zostały przeprowadzone na maszynie wytrzymałościowej z napędem hydraulicznym oraz zapisem cyfrowym. Kształt, wymiary oraz schemat wykonania próby przedstawiono w pracy [5].

Badania wytrzymałości na ścinanie można uznać za pozytywne, jeżeli ścięcie próbki będzie miało miejsce w złączu.

Dr inż. Anna Pocica - Politechnika Opolska, inż. Tomasz Groński - Zakład Technologii Wysokoenergetycznych EXPLOMET. Autor korespondencyjny/Corresponding author: tomasz.gronski@gmail.com 
Tablica I. Skład chemiczny i własności mechaniczne stali ferrytyczno-austenitycznej (LDX)

Table I. Chemical composition and machanical properties of ferriticaustenitic steel (LDX)

\begin{tabular}{|c|c|c|c|c|c|}
\hline \multicolumn{7}{|c|}{ Skład chemiczny stali [\%] } \\
\hline $\mathrm{C}$ & $\mathrm{Cr}$ & $\mathrm{Ni}$ & $\mathrm{Mo}$ & $\mathrm{N}$ & $\mathrm{Mn}$ \\
\hline 0,03 & 21,5 & 1,5 & 0,3 & $0,20 \div 0,25$ & 5 \\
\hline \multicolumn{7}{|c|}{ Właściwości mechaniczne } \\
\hline $\mathrm{R}_{\mathrm{m}}, \mathrm{MPa}$ & $\mathrm{R}, \mathrm{MPa}$ & $\mathrm{A}, \%$ & Twardość, HV \\
\hline 450 & $650 \div 850$ & 30 & 227 \\
\hline
\end{tabular}

Tablica II. Skład chemiczny i własności mechaniczne stali 304L Table II. Chemical composition and mechanical properties of $304 \mathrm{~L}$ steel

\begin{tabular}{|c|c|c|c|c|c|c|c|c|}
\hline \multicolumn{9}{|c|}{ Skład chemiczny stali [\%] } \\
\hline C & Si & $\mathrm{Mn}$ & $\mathrm{P}$ & S & $\mathrm{Cr}$ & $\mathrm{Ni}$ & $\mathrm{N}$ & Inne \\
\hline 0,03 & 1 & 2 & 0,045 & 0,03 & $18 \div 20$ & $10 \div 12$ & 0,11 & - \\
\hline \multicolumn{9}{|c|}{ Właściwości mechaniczne } \\
\hline \multicolumn{3}{|c|}{$\mathrm{R}_{\mathrm{m}}, \mathrm{MPa}$} & \multicolumn{2}{|c|}{$\mathrm{R}_{\mathrm{e}} \mathrm{MPa}$} & \multicolumn{2}{|c|}{$A, \%$} & \multicolumn{2}{|c|}{ Twardość, HV } \\
\hline \multicolumn{3}{|c|}{220} & \multicolumn{2}{|c|}{$520 \div 670$} & \multicolumn{2}{|c|}{45} & \multicolumn{2}{|c|}{200} \\
\hline
\end{tabular}

Tablica III. Własności mechaniczne tytanu (TiGr1) i cyrkonu (Zr700) Table III. Mechanical properties of titanium (TiGe1) and zirconium (Zr700)

\begin{tabular}{|c|c|c|c|c|}
\hline Materiał & $\mathbf{R}_{\mathbf{p 0}, 2}, \mathbf{M P a}$ & $\mathbf{R}_{\mathbf{m}, \mathbf{M P a}}$ & $\mathbf{A}, \%$ & $\mathbf{H V}$ \\
\hline TiGr1 & 346 & 467 & 25,6 & 122 \\
\hline Zr 700 & 150 & 308 & 38 & 170 \\
\hline
\end{tabular}

W przypadku układów trójwarstwowych próbki do badań ścinania można stosować trzy rodzaje próbek: z materiału nakładanego, warstwy pośredniej lub warstwy pośredniej - materiału podstawowego. Próbę przeprowadza się do momentu maksymalnego rozdzielenia materiału rejestrując największą wartość siły, przy której to nastąpiło. Dla złącza Zr-TiLDX wytrzymałość na ścinanie $R_{s}$ wynosiła $471 \mathrm{MPa}$, a ścinanie miało miejsce w złączu Ti-LDX. Plater Ti-304L-LDX miał bardzo zróżnicowaną wytrzymałość na ścinanie. Minimalna wartość $R_{s}$ wynosiła $112 \mathrm{MPa}$, a ścinanie miało miejsce w złączu Ti-304L, maksymalna $R_{s}$ wynosiła $814 \mathrm{MPa}$, a ścinanie nastąpiło w warstwie stali $304 \mathrm{~L}$.

Badanie wytrzymałości na zginanie jest kolejną próbą przewidzianą w normach, mającą na celu ocenę jakości granicy połączenia. W przypadku materiałów platerowanych przepisy nie dopuszczają powstania rozwarstwienia w strefie połączenia. Próbę przeprowadza się do momentu zgięcia próbki o kąt $180^{\circ}$ lub do momentu wystąpienia rozwarstwień w strefie złącza. W przypadku plateru Zr-Ti-LDX nie stwierdzono wystąpienia wad, a kąt gięcia wynosił $180^{\circ}$. Złącze Ti-304L-LDX tylko w dwóch przypadkach nie wykazało wad, przy kącie gięcia $180^{\circ}$. Pozostałe próbki rozwarstwiały się w złączu Ti-304L, przy kącie $20 \div 25^{\circ}$.

Próba wytrzymałości na odrywanie jest dodatkową metodą sprawdzenia wytrzymałości złącza na rozciąganie obok próby zginania. Dzięki tej próbie można wyznaczyć obciążenie, które w stanie jest przenieść złącze. Próbki wykorzystywane w próbie odrywania nie są objęte normą. W przypadku układów trójwarstwowych stosuje się dwa rodzaje prób: wykorzystujące materiał nakładany - warstwę pośrednią oraz warstwę pośrednią - materiał podstawowy. W przypadku badania makroskopowego obserwuje się miejsce oderwania oraz mierzy się maksymalną siłę, przy której następuje zniszczenie próbki. Wytrzymałość na odrywanie $\mathrm{R}_{\circ}$ złącza Zr-Ti-LDX wynosiła $419 \mathrm{MPa}$, a oderwanie nastąpiło w połączeniu Ti-LDX. W drugim platerze minimalna wytrzymałość była równa $57 \mathrm{MPa}$, a maksymalna $327 \mathrm{MPa}$. Oderwanie miało miejsce w połączeniu Ti-304L.

Badania makroskopowe platerów powstałych w wyniku zgrzewania wybuchowego mają na celu obserwację fali powstałej w wyniku połączenia. Do badań wykorzystano mikroskop optyczny, a zarejestrowane makrostruktury przedstawiono na rysunkach 1 i 2.

W obu przypadkach przedstawione złącza faliste wskazują na poprawny dobór parametrów przy zgrzewaniu, a pewna ilość warstwy przetopionej jest dozwolona.

Badanie mikrotwardości wykonano na twardościomierzu Innovatest, przy obciążeniu 5N. Pomiary prowadzono na przekroju prostopadłym do powierzchni połączenia co 0,2 mm. Wyniki pomiarów przedstawiono na rysunkach 3 i 4.

Analizę równoważnej grubości przetopień RGP wykonano zgodnie $z$ metodyką przedstawioną w pracy [3]. Stwierdzono, że we wszystkich złączach wartość RGP wahała się od 0,19 do 0,29 $\mu \mathrm{m}$, czyli w badanych układach występuje mała ilości warstwy przetopionej.

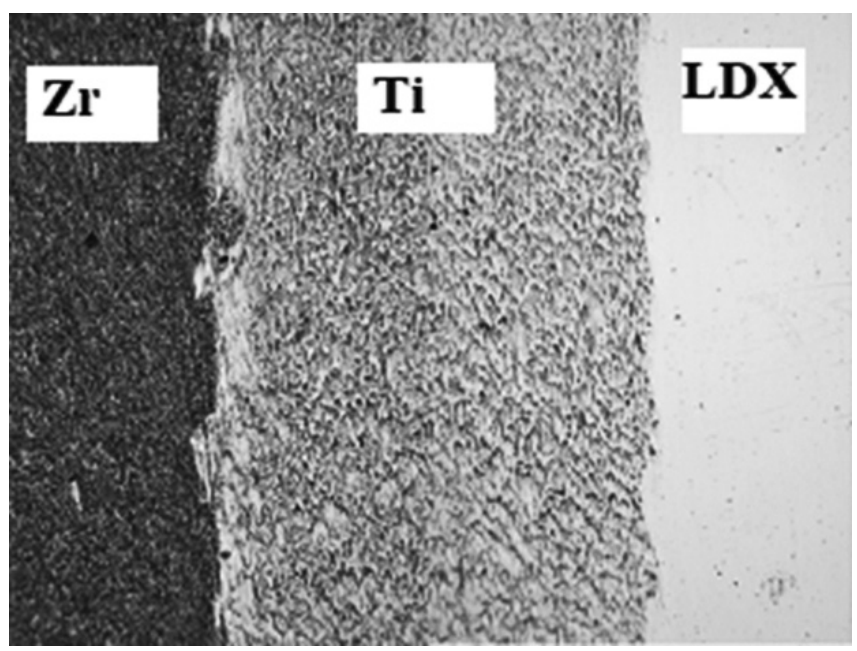

Rys. 1. Złącze faliste Zr-Ti-LDX, pow. 50x

Fig. 1. Corrugated joint of Zr-Ti-LDX, 50x mag.

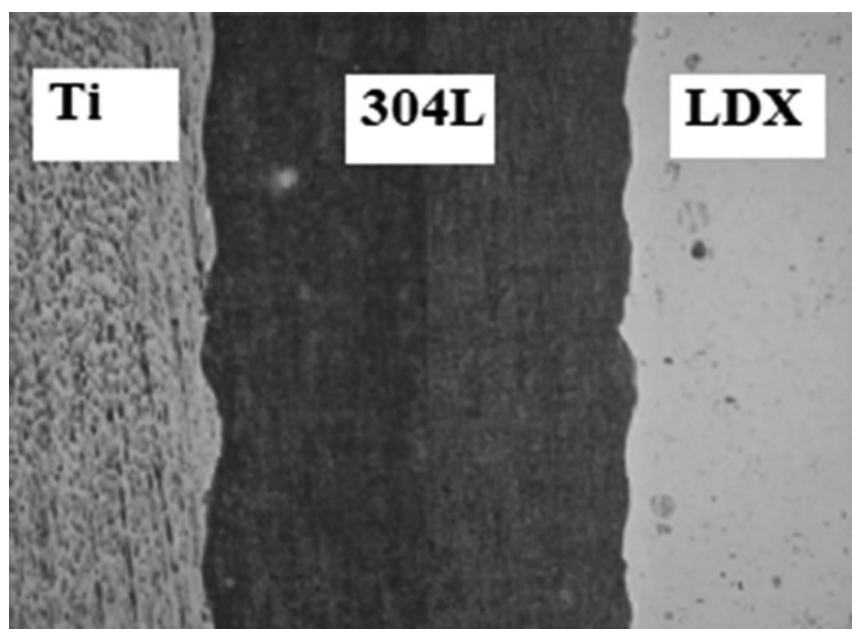

Rys. 2. Złącze faliste Ti-304L-LDX, pow.50x

Fig. 2. Corrugated joint of Ti-304L-LDX, 50x mag. 


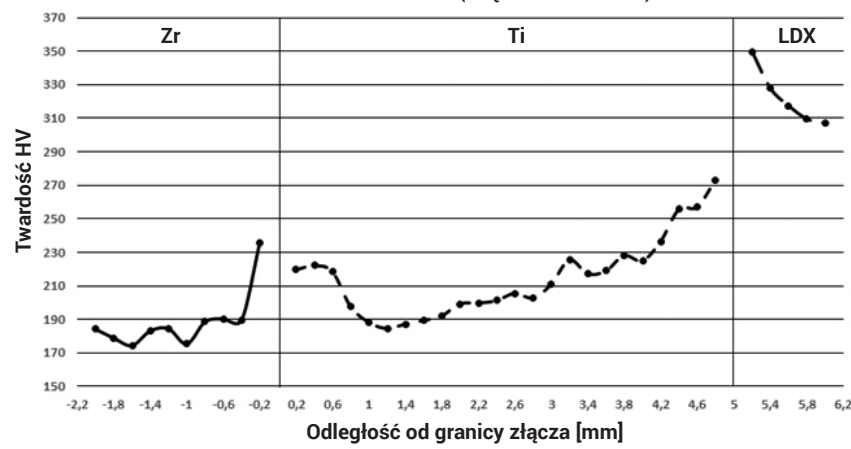

Rys. 3. Rozkład twardości w przekroju poprzecznym złącza Zr-Ti-LDX

Fig. 3. Hardness distribution in cross-section of Zt-Ti-LDX joint

\section{Analiza wyników badań}

Przeprowadzone badania wykazały, że w wyniku zgrzewania wybuchowego uzyskano układy trójwarstwowe o falistym charakterze połączenia, z małą ilością warstwy przetopionej. Wytrzymałość trimetalu Zr-Ti-LDX na ścinanie wynosiła $R_{S}=471 \mathrm{MPa}$ i ponad trzykrotnie przekracza wymaganą przez normę ASTM B898 [6] wartość 140 MPa. Drugi z badanych trimetali tylko w jednym przypadku nie spełniał warunków normy, a w pozostałych badanych próbkach wartość $R_{S}$ była zdecydowanie wyższa i wynosiła $217 \div 814 \mathrm{MPa}$. Również przy badaniach wytrzymałości na odrywanie złącza Zr-Ti-LDX zanotowano zbliżone wartości, $\mathrm{R}_{\circ}=410 \mathrm{MPa}$. W przypadku drugiego plateru wytrzymałość wahała się od $57 \mathrm{MPa}$ do $327 \mathrm{MPa}$. Niskie wartości wytrzymałości sugerują, że źle został przeprowadzony proces zgrzewania wybuchowego lub nieprawidłowo dobrano parametry zgrzewania.

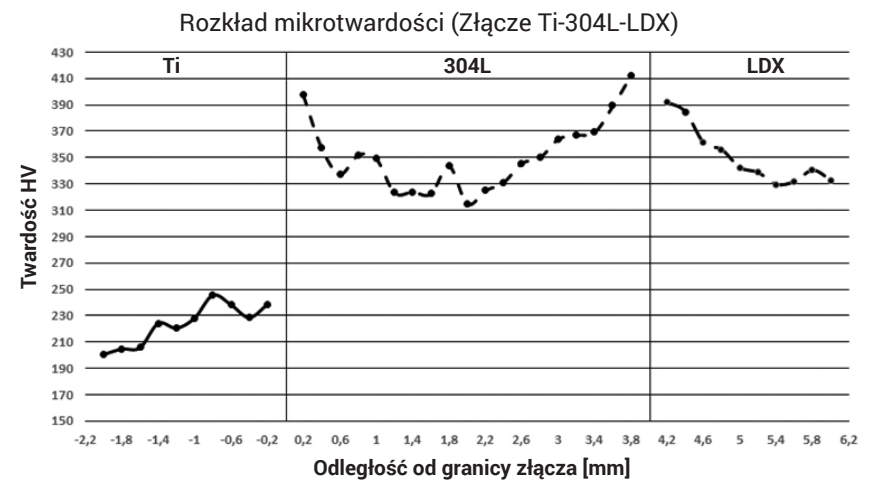

Rys. 4. Rozkład twardości w przekroju poprzecznym złącza Ti-304L-LDX Fig. 4. Hardness distribution in cross-section of Ti-304L-LDX joint

Wyniki badania wytrzymałości na zginanie wykazały, że dla układu Ti-304L-LDX głównym miejscem rozwarstwienia było złącze 304L-LDX. Pojedyncze przypadki ujawniły rozwarstwienie $\mathrm{w}$ materiale podstawowym. Kąt, przy którym nastąpiło rozwarstwienie materiału wahał się od $15^{\circ}$ do $25^{\circ}$. Dla układu Zr-Ti-LDX nie stwierdzono występowania rozwarstwienia w złączach oraz w materiałach tworzących plater.

Platerowanie wybuchowe spowodowało umocnienie materiałów. W obu przypadkach zaobserwowano wzrost twardości w kierunku granicy połączenia, przy czym maksymalną twardość zanotowano w odległości 0,2 mm od linii złącza, zarówno w materiale bazowym, jak i w międzywarstwie i materiale nakładanym. Większe umocnienie obserwuje się w złączach trimetalu Ti-304L-LDX, co może tłumaczyć gorsze wyniki prób zginania i odrywania tego połączenia. Może to tłumaczyć gorsze wyniki prób zginania i odrywania tego połączenia.

\section{Wnioski}

Na podstawie przeprowadzonych badań sformułowano następujące wnioski:

1. W procesie zgrzewania wybuchowego uzyskano złącza o falistym charakterze, z małą ilością warstwy przetopionej, co wpływa pozytywnie na jakość połączenia.

2. Wszystkie złącza wykazują maksymalne umocnienie w odległości 0,2 mm od linii złącza.

3. Trimetal Zr-Ti-LDX w porównaniu z trimetalem Ti-304L-LDX cechują lepsze własności mechaniczne i mniejsze umocnienie złączy.

\section{Literatura}

[1] Groński T.: Stosowanie i wytwarzanie układów trójwarstwowych do budowy elementów aparatury procesowej, Praca dyplomowa inżynierska, Politechnika Opolska, 2018.

[2] Prażmowski M., Rozumek D., Paul H.: Static and fatigue tests of bimetal Zr-steel made by explosive welding, Engineering Failure Analysis vol. 75, pp. 71-81, 2017.

[3] Walczak W.: Zgrzewanie wybuchowe metali i jego zastosowanie, WNT, Warszawa, 1989
[4] Prażmowski M. Rozumek D.: Rozwój pęknięć przy cyklicznym zginaniu w złączu cyrkon-stal powstałych w wyniku zgrzewania wybuchowego, Przegląd Spawalnictwa, nr 4, s. 45-50, 2014.

[5] Prażmowski M.: Mechanical properties of zirconium/steel bimetal fabricated by means of explosive welding at varied detonation velocities, Archives of Metallurgy and Materials, vol. 59, pp.1137-1142, 2014.

[6] ASTM B898: Standard Specification for Reactive and Refractory Metal Clad Plate 